\title{
Activation of the Hh Pathway in Periosteum-Derived Mesenchymal Stem Cells Induces Bone Formation in Vivo
}

\section{Implication for Postnatal Bone Repair}

Qun Wang, Chunlan Huang, Fanjie Zeng, Ming Xue, and Xinping Zhang

From the Center for Musculoskeletal Research, University of Rochester, School of Medicine and Dentistry, Rochester, New York

While the essential role of periosteum in cortical bone repair and regeneration is well established, the molecular pathways that control the early osteogenic and chondrogenic differentiation of periosteal stem/progenitor cells during repair processes are unclear. Using a murine segmental bone graft transplantation model, we isolated a population of early periosteum-callus-derived mesenchymal stem cells (PCDSCs) from the healing autograft periosteum. These cells express typical mesenchymal stem cell markers and are capable of differentiating into osteoblasts, adipocytes, and chondrocytes. Characterization of these cells demonstrated that activation of the hedgehog $(\mathrm{Hh})$ pathway effectively promoted osteogenic and chondrogenic differentiation of PCDSCs in vitro and induced bone formation in vivo. To determine the role of the Hh pathway in adult bone repair, we deleted Smoothened (Smo), the receptor that transduces all Hh signals at the onset of bone autograft repair via a tamoxifen-inducible RosaCreER mouse model. We found that deletion of Smo markedly reduced osteogenic differentiation of isolated PCDSCs and further resulted in a near $50 \%$ reduction in periosteal bone callus formation at the cortical bone junction as determined by MicroCT and histomorphometric analyses. These data strongly suggest that the $\mathrm{Hh}$ pathway plays an important role in adult bone repair via enhancing differentiation of periosteal progenitors and that activation of the Hh pathway at the onset of healing could be beneficial for repair and regeneration. (Am J Pathol 2010, 177:3100-3111; DOI: 10.2353/ajpath.2010.100060)

Periosteum plays a key role in repair and regeneration via activation of multipotent mesenchymal stem cells
(MSCs). ${ }^{1-2}$ After fracture or osteotomy, periosteum undergoes a unique morphogenic process that, to some extent, recapitulates the fundamental features of bone and cartilage differentiation in the developing limb. ${ }^{3-4}$ Within a few days after injury, periosteum becomes thickened due to activation and proliferation of the residing mesenchymal stem/progenitor cells. These stem/progenitor cells proceed to differentiate into osteoblasts or chondrocytes and eventually form bone via both intramembranous and endochondral pathways. Endochondral bone formation takes place at the cortical bone junctions where the blood supply is poor. Intramembraneous bone formation proceeds with robust matrix mineralization distal to cortical junctions where blood supply is better preserved. ${ }^{5-6}$ The success of bony union at the cortical bone junction heavily depends on the efficient and coordinated expansion and differentiation of periosteal progenitor cells at the cortical junction, a process that is precisely controlled by integrated molecular pathways. ${ }^{6-7}$

The Hedgehog pathway plays a critical role in controlling self-renewal, migration, differentiation, and cell fate commitment of embryonic as well as adult stem or progenitor cells. ${ }^{8-9}$ All hedgehog $(\mathrm{Hh})$ proteins consist of a signal peptide with a highly conserved $\mathrm{N}$-terminal region (signaling peptide) and a more divergent C-terminal region. Because the amino acid sequence is highly conserved, $\mathrm{Hh}$ ligands are functionally interchangeable. The N-terminal fragment of $\mathrm{Hh}$ (ie, the ShhN) is the active form for all $\mathrm{Hh}$

Supported by Musculoskeletal Transplant Foundation, NYSTEM grant N08G495, National Institutes of Health grants RC1AR058435, AR051469, AR048681, and P50AR054041, and a grant from Finger Lake Eye and Tissue Bank.

Accepted for publication August 11, 2010.

Supplemental material for this article can be found on http://ajp. amjpathol.org.

Address reprint requests to Dr. Xinping Zhang, The Center for Musculoskeletal Research, University of Rochester Medical Center, 601 Elmwood Avenue, Rochester, NY 14642. E-mail: Xinping_Zhang@URMC. rochester.edu. 
signaling. ${ }^{10}$ All Hh signals are transduced through Smoothened (Smo), a G protein-coupled receptor with specificity toward Gi proteins. ${ }^{11-15}$ Hh-targeted cells express two components of the Hh receptor complex on the cell surface: Smoothened (Smo) and Patched (Ptc). Ptc represses the activity of Smo, which regulates proteolytic processing of downstream zinc-finger transcription factors Gli1, 2, and 3. Gli2 is more potent as an activator, whereas Gli3 is more powerful as a repressor. ${ }^{16-18}$

The Hh pathway plays a critical role in skeletogenesis that implicates mesenchymal precursors. ${ }^{9,19}$ Sonic hedgehog (Shh) is crucial for the induction of the sclerotome, whereas Indian hedgehog (Ihh) is essential for perichondrium progenitor cell differentiation and collarbone formation during limb development. ${ }^{20-25}$ In vitro studies using embryonic mesenchymal stem cell lines such as C3H10T1/2 show that activation of the Hh pathway stimulates osteoblastogenesis via activation of Gli2. ${ }^{26-29}$ There are also reports that show the potential stimulatory effects of $\mathrm{Hh}$ signaling on lineage differentiation of primary human mesenchymal stem cells in vitro. ${ }^{30}$ Notwithstanding all these studies, the role of the Hh pathway in postnatal endochondral bone repair and its prospect in mesenchymal stem cell-mediated bone and cartilage regeneration remain unknown. A comprehensive knowledge of these pathways in bone repair will be important to the optimization of future pathway-targeted strategies for treatment of bony defects.

The lack of a defined phenotype and cellular markers for mesenchymal progenitor cells significantly hampers the efforts to track cell fate and further understand the molecular pathways underlying the expansion and differentiation of periosteal progenitor cells during repair processes. We previously established a segmental bone graft transplantation model in mice that permits molecular and cellular analyses of periosteum's contribution to bone graft healing and incorporation. ${ }^{31}$ Using this model, we tracked periosteal cell fate and examined the unique periosteum tissue morphogenesis during bone graft healing. ${ }^{32-34}$ We found that the expansion and further differentiation of the progenitor cells accounted for about $70 \%$ of bone and cartilage formation during the initiation stage of healing. Although these cells were eventually remodeled and replaced by host bone, the formation of donor cell-derived callus was essential for the initiation of bone graft healing. The removal of the donor periosteum resulted in the elimination of bone formation and marked impairment of bone graft healing. ${ }^{33}$ Further engraftment of multipotent mesenchymal stem cells on devitalized bone allografts improves healing and graft incorporation. ${ }^{32-33}$

With the goal of understanding the molecular pathways that regulate periosteal mesenchymal cell differentiation during cortical repair, in this study we isolated a population of early periosteum-derived mesenchymal stem cells (PCD$\mathrm{SCs}$ ) from the healing bone autografts. These isolated cells express the typical mesenchymal stem cell markers (Sca-I, CD105, SSEA-4, CD29, and CD140) and are capable of differentiating into osteoblasts, adipocytes, and chondrocytes. Further characterization of these cells demonstrated that activation of hedgehog signaling was extremely effective in driving bone formation in vivo. Furthermore, using a Tamoxifen (TM)-inducible RosaCreER mouse model that allows efficient deletion of genes during initiation of adult repair, ${ }^{35-36}$ we demonstrated that disruption of $\mathrm{Hh}$ signaling by postnatal deletion of Smo significantly reduced periosteal bone callus formation.

\section{Materials and Methods}

\section{Experimental Animals and Materials}

Smo ${ }^{f / f}$, Ptch1-LacZ heterozygotes, RosaCreER, GFP transgenic mice were purchased from the Jackson Laboratory (Bar Harbor, ME). Immunocompromised mice (bg-nu/nu-xid) were purchased from Harlan Sprague Dawley Inc (Indianapolis, IN). All animal surgeries were performed on 8- to 10-week-old adult mice. All procedures were approved by the Institutional Committee of Animal Resources.

The Hh agonist Purmorphamine (Cayman Chemicals, Ann Arbor, MI) was used at $2 \mu \mathrm{mol} / \mathrm{L}$ in all in vitro experiments. Hh inhibitor Cyclopamine was used at indicated doses according to the manufacturer (Toronto Research Chemical Inc., North York, Ontario). Adenovirus encoding green fluorescence protein (Ad-GFP) and N-terminal peptide of human Shh $(\mathrm{ShhN})^{37}$ were kindly provided by Dr. Philip Leopold (Weill Medical College of Cornell University, New York, NY). Adenovirus encoding recombinant human BMP-2 was purified as previously described. ${ }^{33}$ Tamoxifen (TM) (Sigma-Aldrich, St. Louis, MO) was administered via peritoneal injection at a dose of $1 \mathrm{mg} / 10 \mathrm{~g}$ of body weight. Tamoxifen (TM) was injected every other day before and after surgery for a maximum of 5 doses. ${ }^{36,38}$

\section{Segmental Bone Graft Transplantation Model}

The femoral bone graft transplantation was performed as previously described. ${ }^{33,39-40}$ Briefly, 10-week-old recipient mice were anesthetized by peritoneal injection of a mix of 10 $\mathrm{mg} / \mathrm{ml} \mathrm{Ketamine} \mathrm{and} 1 \mathrm{mg} / \mathrm{ml}$ Xylazine. A 4-mm mid-diaphyseal segment was removed from the femur of the donor mice using a sharp diamond-cutting wheel attached to a cordless Dremel (Dremel Minimite model 750). Grafts were carefully dissected to remove the muscles without compromising the periosteum and immediately used to reconstruct a 4-mm segmental defect in the same mouse (autograft) or mice of the same strain (isograft). In the indicated experiments, we used live bone grafts from GFP transgenic mice as donor and the wild-type littermates as recipients. The bone graft was stabilized using a 25G stainless pin placed through intramedullary marrow cavity.

\section{Isolation of Periosteal Mesenchymal Stem Cells from Donor Bone Graft}

To isolate mesenchymal progenitor cells from autograft periosteum, live bone isograft transplantation was performed between GFP transgenic mice and their wild-type littermates. Donor $\mathrm{GFP}^{+}$grafts were collected at day 5 posttransplantation. Bone marrow was removed by repeated flushing of the marrow cavities with serum-free $\alpha$-MEM medium. Tissues attached to the periosteal surface 
of the donor grafts were scraped off and pooled in a Petri dish. After digestion with Collagenase D (Roche Applied Science, Indianapolis, IN) at a concentration of $1 \mathrm{mg} / \mathrm{ml}$ for 1 hour, all cells were pooled and suspended in $\alpha$-MEM medium containing $1 \%$ penicillin and streptomycin, $1 \%$ glutamine, and $20 \%$ fetal bovine serum (FBS). Cells were allowed to adhere to the culture dish and grow to confluence. Cells collected from the second and third passage were used for differentiation assay and fluorescence activated cell sorting (FACS) analyses for mesenchymal stem cell surface markers. In other indicated experiments, autograft transplantations were performed in various mouse models including $\mathrm{Smo}^{\mathrm{fff}}$ and $\mathrm{Smo} \mathrm{f}^{\mathrm{fff}} ;$ CreER mice. Periosteal progenitors were subsequently isolated from the donor graft periosteum on day 5 postgrafting.

\section{FACS Analyses}

Cells were suspended in phosphate-buffered saline containing 4\% FBS. Phycoerythrin-coupled antibodies against CD34, CD45, CD133, CD105, SSEA-4, CD29, CD140 were used to stain cell surface markers. FACS analyses were performed using FACS Calibur at the Flow Cytometry Core facility. In some indicated experiments, GFP+ cells were sorted to $99 \%$ purity and used for differentiation analyses.

\section{Multilineage Differentiation Analyses}

For adipogenesis assay, cells were cultured with $\alpha \mathrm{MEM}$ medium containing horse serum (12.5\%), FBS (12.5\%), penicillin/streptomycin $(50 \mathrm{U} / \mathrm{ml})$, and hydrocortisone $\left(10^{-4} \mathrm{~mol} / \mathrm{L}\right)$. Cultures were harvested on day 10 for Oil Red $\mathrm{O}$ staining and RNA analyses to examine PPARy2 and $C E B P \beta$ gene expression. For osteogenesis assay, cells were cultured with fresh osteogenic differentiation media containing $10 \mathrm{mmol} / \mathrm{L} \beta$-glycerolphosphate and 50 $\mu \mathrm{mol} / \mathrm{L}$ ascorbic acid. Cells were harvested at indicated times for alkaline phosphatase (ALP) staining and gene analyses. For chondrogenesis assay, a total of $2 \times 10^{5}$ cells in $10 \mu$ l of media were placed as micromass in the center of a 24-well plate and incubated in $5 \% \mathrm{CO}_{2}$ at $37^{\circ} \mathrm{C}$ for 1 hour. Basic chondrogenic differentiation medium containing high glucose DMEM supplemented with 1\% ITS-Premix, Lascorbic acid-2-phosphate $(0.1 \mathrm{mmol} / \mathrm{L})$, dexamethasone $\left(1 \times 10^{7} \mathrm{~mol} / \mathrm{L}\right)$, proline $(400 \mu \mathrm{g} / \mathrm{ml})$ and TGF $\beta(10 \mathrm{ng} / \mathrm{ml})$ was added. Pellets were harvested on day 7 for Alcian Blue staining. A total of four pellets from each group were pooled for RNA analyses. In indicated experiments, adenovirus expressing human BMP-2 or ShhN was used to infect isolated cells before the micromass culture.

\section{In Vivo Ectopic Bone Formation in Nude Mice}

PCDSCs were isolated from the donor autografts of GFP transgenic mice. Cells were infected with control adenovirus Ad-GFP or Ad-ShhN at a multiplicity of infection (MOI) of 10 or 100 . A total of $1 \times 10^{6}$ cells were seeded onto a collagen scaffold (BD Bioscience, Franklin Lakes, $\mathrm{NJ}$ ) and implanted subcutaneously into athymic nude mice as previously described. ${ }^{41-42}$ Implants were har- vested 8 weeks after surgery, and bone formation was determined by microCT and histology. To determine the incorporation of donor GFP+ progenitors into bone tissue, implants were fixed in $4 \%$ paraformaldehyde followed by decalcification in 10\% EDTA for 2 weeks. Cryosections were prepared and GFP+ cells were visualized and photographed using a Zeiss Axio Imager.

\section{In Situ Hybridization}

\begin{abstract}
${ }^{35}$ S-UTP-labeled sense and antisense riboprobes against murine Shh or Ihh genes were synthesized from a plasmid (kindly provided by Dr. Matthew Hilton) as previously described. ${ }^{43-44}$ The specific activity of the probes was determined by radioactivity. The sections were incubated in hybridization buffer ( $50 \%$ formamide, $0.3 \mathrm{M} \mathrm{NaCl}, 20 \mathrm{mmol} / \mathrm{L}$ Tris-HCl, 5 mmol/L EDTA, 10\% dextran sulfate, $0.02 \%$ Ficoll, $0.02 \%$ BSA, $0.02 \%$ polyvinyl pyrrolidone, and $0.5 \mathrm{mg} / \mathrm{ml}$ yeast RNA) containing riboprobe at $10,000 \mathrm{cpm} / \mu$ l. Hybridization was performed at $55^{\circ} \mathrm{C}$ overnight. Emulsion-dipped slides were exposed for about 7-14 days depending on the intensity of the signals. Anti-sense probes of Ihh were further used as controls for the experiment.
\end{abstract}

\section{Immunohistochemical Staining for PCNA}

Immunohistochemical staining for the nuclear antigen PCNA protein was performed using a staining kit purchased from Zymed (S. San Francisco, CA). The staining procedures were followed as instructed by the manufacturer. To determine the number of $\mathrm{PCNA}^{+}$cells, three sections of each sample were used to count the positive cells in periosteal callus. The mean of the three sections represented each sample. A group of three samples was included for each time point. The mean from three samples divided by the average of the area of the periosteal callus was used in statistical analyses.

\section{Real-Time PCR Analyses}

Total RNA was prepared using a Qiagen RNA extraction kit. Exactly $0.5 \mu \mathrm{g}$ of mRNA per callus was pooled and used in reverse transcription to make single-strand cDNA. Single-strand cDNA was synthesized using a commercial first strand cDNA synthesis kit (Invitrogen). Quantitative RT-PCR reaction was performed using SyberGreen (ABgene, Rochester, NY) in a RotorGene real time PCR machine (Corbett Research, Carlsbad, CA). All genes were compared to a standard $\beta$-actin control. Data were assessed quantitatively using analysis of variance comparing relative levels of transcript expression as a function of time. All primers used for the assessment can be found in the Table 1.

\section{MicroCT Imaging Analyses}

Femurs were harvested at day 17 postgrafting and scanned using a Viva microCT system (Scanco Medical, Bassersdorf, Switzerland) at a voxel size of $10.5 \mu \mathrm{m}$ to 
Table 1. Primers

\begin{tabular}{|c|c|c|}
\hline Genes & Primer forward & Primer reverse \\
\hline \multicolumn{3}{|l|}{ Murine } \\
\hline actin & 5'-AGATGTGGATCAGCAAGCAG-3' & 5'-GCGCAAGTTAGGTTTTGTCA-3' \\
\hline Smo & $5^{\prime}$-GACCACTCCCATAAGGGCTA-3' & 5'-GAAGAGGTTGGCCTAGTGGA-3' \\
\hline Col $X$ & 5'-CTTTGTGTGCCTTTCAATCG-3' & 5'-GTGAGGTACAGCCTACCAGTTTT-3' \\
\hline $\mathrm{Col} / 1$ & $5^{\prime}-$ CCACACCAAATTCCTGTTCA-3' & $5^{\prime}$-ACTGGTAAGTGGGGCAAGAC-3' \\
\hline PPARr & 5'-AGGCCGAGAAGGAGAAGCTGTTG-3' & 5'-TGGCCACСTCTTTGCTCTGCTC-3' \\
\hline$C / E B P$ a & 5'-GAGCGCCATCGACTTCAG-3' & 5'-CTTGCGCACAGCGATGTT-3' \\
\hline Osx & 5'-ACTGGCTAGGTGGTGGTCAG-3' & 5'-GGTAGGGAGCTGGGTTAAGG-3' \\
\hline Bmp-2 & 5'-TGGAAGTGGCCCATTTAGAG-3' & 5'-GCTTTTCTCGTTTGTGGAGC-3' \\
\hline$O C$ & $5^{\prime}$-AGGGAGGATCAAGTCCCG-3' & $5^{\prime}-$ GAACAGACTCCGGCGCTA-3' \\
\hline$A L P$ & 5'-TTGTGCGAGAGAAAGAGAGAGA-3' & 5'-GTTTCAGGGCATTTTTCAAGGT-3' \\
\hline Ptc1 & 5'-TTCTGCTGCCTGTCCTCTTA-3' & $5^{\prime}-$ GCAAACCGGACGACACTT-3' \\
\hline Gli1 & 5'-TTGTCCAGCTTGGATGAAGG-3' & 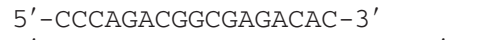 \\
\hline SFRP-1 & 5'-СССТCCAAGGCTTGAGTAAAAG-3' & $5^{\prime}-$ AGCACATGCATAGGCGGTGTA-3' \\
\hline SFRP-2 & 5'-ATCCGCAAGCTGCAATGCTA-3' & 5'-TGTGCTTGGGAAACCGGAAA-3' \\
\hline \multicolumn{3}{|c|}{ (5) - } \\
\hline Bmp2 & 5'-CCTCAGCAGAGCTTCAGGTT-3' & 5'-TGCTTGCATTCTGATTCACC-3' \\
\hline Shh & $5^{\prime}$-ACTCCGAGCGATTTAAGGAACT-3' & $5^{\prime}$-CAGACGTGGTGATGTCCACTG-3' \\
\hline
\end{tabular}

image bone. New bone formation was measured as previously described. ${ }^{33,40}$ The threshold was chosen using $2 \mathrm{D}$ evaluation of several slices in the transverse anatomical plane so that mineralized callus were identified while surrounding soft tissue was excluded. An average threshold of 220 was optimal and used uniformly for all samples. Each sample was contoured around the external callus and along the edge of the cortical bone, excluding the marrow cavity. New bone volume was measured on the surface of the host and donor side in bone autografted samples as previously described. ${ }^{33,40}$

\section{Histology and Analyses}

LacZ staining was performed on cryosections obtained from periosteal callus of Ptch1-LacZ mice. Staining was carried out as previously described. ${ }^{33}$ Briefly, fresh femur samples were fixed in $0.2 \%$ glutaraldehyde at $4^{\circ} \mathrm{C}$ for 4 days and decalcifed in EDTA at $4^{\circ} \mathrm{C}$ for 14 days. After complete decalcification, samples were immersed in $30 \%$ sucrose at $4{ }^{\circ} \mathrm{C}$ overnight, and then embedded in OCT medium for cryosectioning. All slides were stained in X-gal solution $(0.02 \%$ NP40, $10 \mathrm{mmol} / \mathrm{L}$ EDTA, 0.02\% glutaraldehyde, $0.05 \% \mathrm{X}$-gal and $2 \mathrm{mmol} / \mathrm{L} \mathrm{MgCL2}$ in phosphate buffer, $\mathrm{PH}$ 7.5) for 24 hours. $\beta$-gal-positive cells were visualized and photographed under light microscopy.

For specimens harvested for histomorphometric analyses, all samples were prepared via paraffin sections. Alcian blue and Orange $G$ staining was used to examine the bone and cartilage formation as previously described. ${ }^{43}$ Histomorphometric analyses were performed using Osteometrics software to determine the area of bone, cartilage, and mesenchyme (total callus subtracted from bone and cartilage tissue) by tracing in the computer program. The percent areas of bone, cartilage, and mesenchyme were used for analyses. For histomorphometric analyses, the mean of at least three nonconsecutive sections represented one sample. At least 15 samples were included in each group for analyses. The mean from 15 samples was used in statistical analyses to determine the composition of the bone graft callus. Cortical bone was excluded from the histomorphometric analyses.

\section{Statistical Analysis}

Data are expressed as a mean value plus or minus the SEM. Statistical significance between experimental groups was determined using one-way analysis of variance and a Tukey's post hoc test. A $P$ value $<0.05$ was considered statistically significant. Data analysis was performed using GraphPad Prism version 5.0 (GraphPad Software, San Diego, CA).

\section{Results}

\section{Isolation and Characterization of a Population of Periosteal Mesenchymal Stem Cells from Autograft Periosteum}

Previously, we have demonstrated an approach of using bone graft marked by $\beta$-galactosidase from R26A mice to track periosteum cell fate during cortical bone graft healing. ${ }^{33}$ A similar approach described in the Materials and Methods section was used to transplant GFP marked bone graft into a wild-type mouse recipient to isolate early periosteum-derived mesenchymal progenitors. FACS analyses showed that about $60 \%$ of the isolated cells were $\mathrm{GFP}^{+}$, indicating donor origin (Figure 1, A and B). About $98 \%$ of the isolated cells expressed stem cell marker Sca-1. Less than 1\% of the cells were positive for hematopoietic lineage marker CD45, CD34, and CD133, whereas more than $90 \%$ of the cells were positive for SSEA-4 (the stage-specific embryonic antigen-4), a MSC marker recently identified from bone marrow. ${ }^{45}$ In addition to SSEA-4, these cells were also positive for known MSC markers such as CD105, CD140, and CD29.

To determine the multilineage differentiation potential of these cells in vitro, we sorted the GFP + cells and treated the cells with lineage-specific differentiation me- 
A

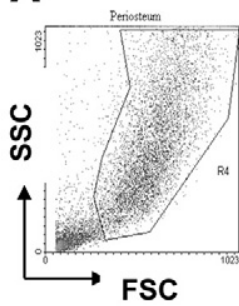

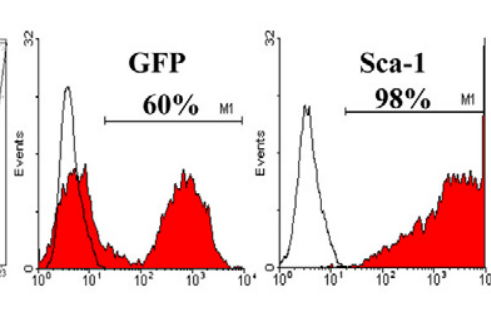

GFP

\section{. \\ B}

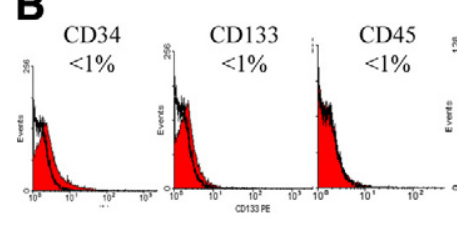

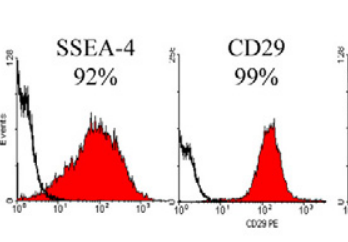

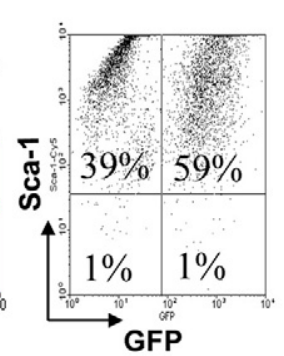

GFP
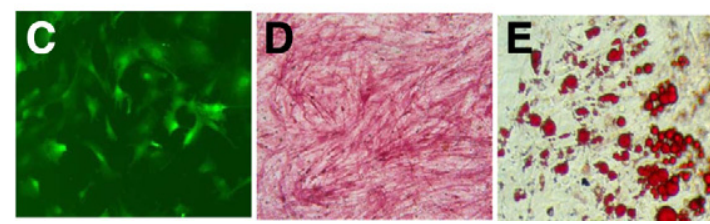
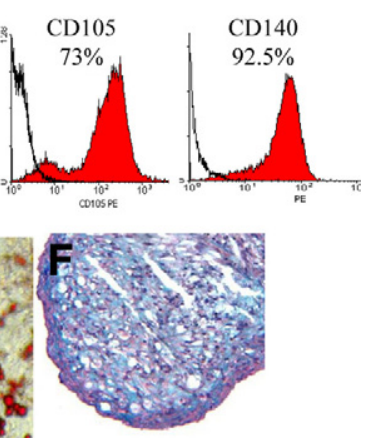

Figure 1. Characterization of PCDSCs in vitro. Cells were isolated from $\mathrm{GFP}^{+}$donor grafts as described. A: FACS analyses show that $60 \%$ of these isolated cells are $\mathrm{GFP}^{+}$, indicating donor origin. Nearly all GFP + cells are also Sca-I positive. B: Further FACS analyses for cell surface markers demonstrate a uniform cell population negative for CD34, CD133, and CD45 but positive for mesenchymal stem cell markers, such as SSEA-4, CD29, Sca-1, CD105, and CD140. C: $\mathrm{GFP}^{+}$donor cells can be sorted and further expanded in culture. These cells can differentiate into osteoblasts (D) positive for ALP staining, adipocytes (E) positive for Oil Red staining, and chondrocytes (F) positive for Alcian Blue staining. dia. As shown in Figure $1(\mathrm{C}-\mathrm{F})$, treatment of the cells with the osteogenic media led to marked induction of osteogenic differentiation as indicated by ALP (Figure 1D). Treatment of the cells with adipogenic media led to robust adipocyte formation as indicated by Oil Red staining (Figure 1E) and induction of PPAR $\gamma$ and CEBP $\alpha$ (data not shown). Treatment of the cells with chondrogenic media containing BMP-2 (100 $\mathrm{ng} / \mathrm{ml})$ in a micromass (or pellet) culture resulted in the formation of chondrocytes as indicated by Alcian Blue staining (Figure 1F) as well as Col2a1 and ColX expression (data not show). Further characterization and comparison of the PCDSCs with stem/progenitor cells derived from other sources such as fat and bone marrow showed that PCDSCs are highly proliferative and more responsive to BMP-2 in osteogenic and chondrogenic differentiation assays than those comparable mesenchymal progenitors isolated from fat or bone marrow. In addition, we found that the basal expressions of Gli homologs were higher in these cells than mesenchymal progenitors derived from other sources (Supplemental Figures 1, A-D and 2, A-E at http://ajp.amjpathol.org).

\section{Activation of the Hh Pathway in Periosteal Mesenchymal Progenitors Enhances Osteogenic and Chondrogenic Differentiation in Vitro and Induces Bone Formation in Vivo}

Osteogenic differentiation of PCDSCs in response to various growth factors was examined in vitro. Isolated PCDSCs were capable of spontaneously differentiating into ALP+ cells with enhanced expression of osteocalcin and OSX over 21-day period in the presence of ascorbic acid and $\beta$-glycerolphosphate (Figure 2A). In the presence of growth factors such as BMP-2, PTH, or PGE2, osteogenic differentiation was further enhanced (data not shown).
Purmorphamine, a potent agonist of Hh, was found to be extremely effective in inducing the osteogenic differentiation and mineralization of PCDSCs (Figure 2, A and B). Gene analyses showed that the Hh agonist strongly induced a panel of osteogenic marker gene expression (Figure 2B). Purmorphamine also significantly increased BMP-2 gene expression in PCDSCs. In addition to the BMP-2 pathway, we found a strong inhibition of the expressions of SFRP 1 and 2, the antagonists of canonical Wnt signaling pathway ${ }^{46}$ by Purmorphamine, suggesting the involvement of the Wnt signaling pathway downstream of $\mathrm{Hh}$ activation.

$\mathrm{N}$-terminal Shh peptide (ShhN) has been used as a strong agonists for all Hh pathways. ${ }^{10,26}$ An adenovirus that expresses a human ShhN (Ad-ShhN) was used to enhance $\mathrm{Hh}$ signaling in PCDSCs. When placed in a monolayer culture, which favors osteogenic differentiation, Hh overexpression led to enhanced osteoblastic differentiation in synergies with BMP-2 (data not shown). When placed in a micromass culture which favors chondrogenic differentiation, ShhN alone appeared to have limited effects. However, ShhN strongly synergized with recombinant human BMP-2 to enhance chondrogenic differentiation as indicated by enhanced Alcian Blue staining and strong expression of $\mathrm{Col} 2 \mathrm{a} 1$ and $\mathrm{Col} X$ expression (Figure 3, A and B).

To determine whether isolated periosteal mesenchymal progenitors can form bone in vivo, we isolated PCDSCs from the bone autograft periosteum of the GFP transgenic mice and implanted the GFP-tagged PCDSCs into immunocompromised nude mice using a well-characterized subcutaneous ectopic bone formation model. ${ }^{41}$ As shown in Figure 4, PCDSCs alone did not form bone over an 8-week period. However, PCDSCs overexpressing ShhN induced a dose-dependent robust bone formation in vivo ( $n=3, P<0.01$, Figure $4, \mathrm{~A}$ and $\mathrm{B})$. Histological analyses demonstrated that the donor PCDSCs 

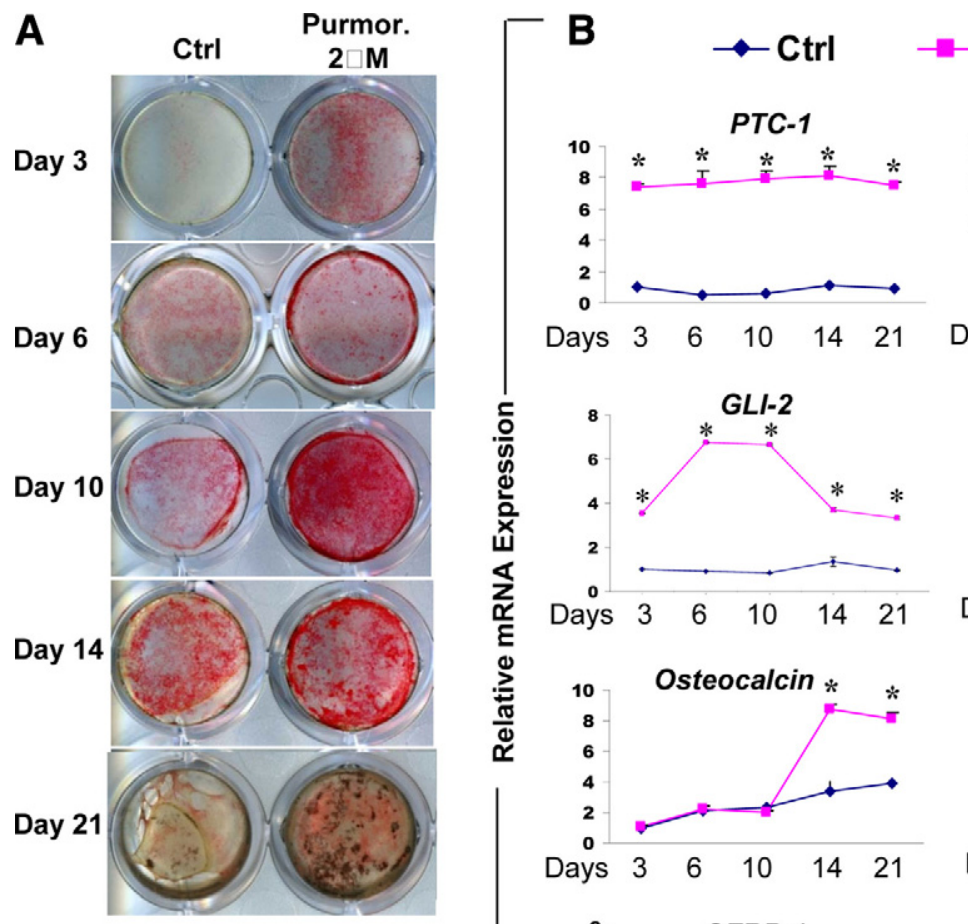

- Purmorphamine
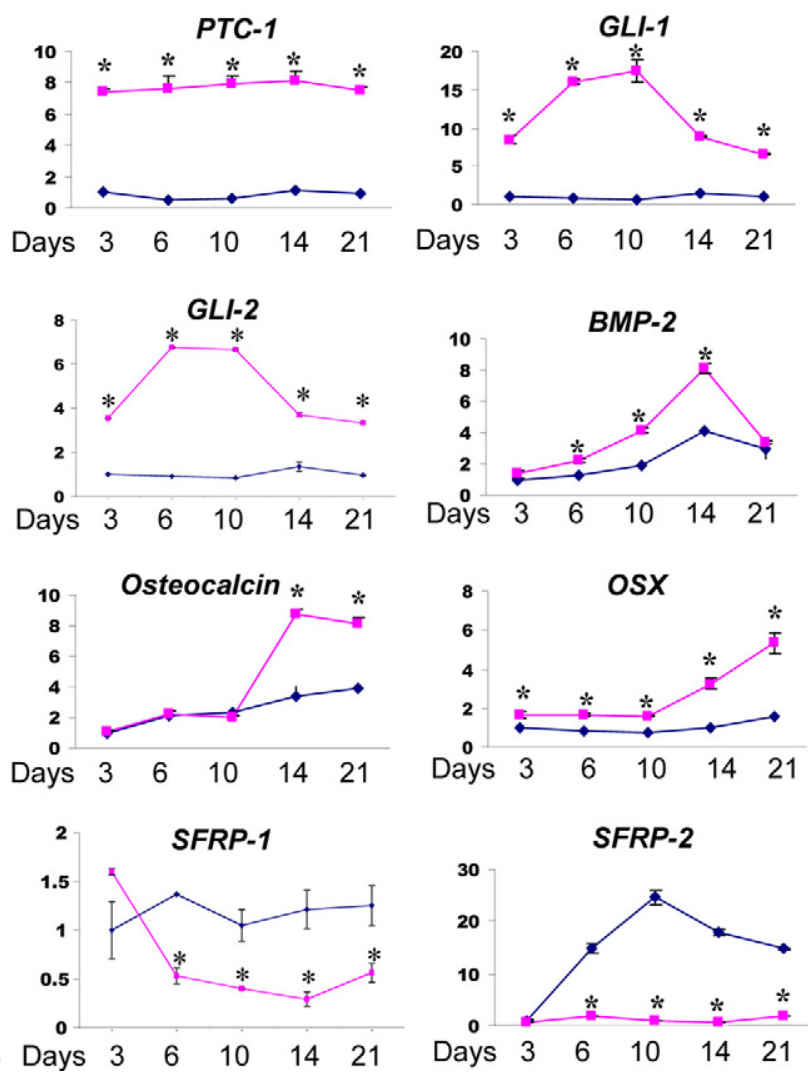

Figure 2. Osteogenic differentiation and mineralization of PCDSCs with or without Hh activation. A: ALP staining demonstrates differentiation of PCDSCs over 21 days in the presence or absence of purmorphamine $(2 \mu \mathrm{mol} / \mathrm{L})$. Note that Van Kossa staining at day 21 shows marked induction of mineralization after treatment of purmorphamine. B: Real time RT-PCR analyses demonstrate the expression profile of Ptc-1, Gli1, Gli2, BMP-2, Osteocalcin, OSX, SFRP1, and SFRP2 genes during differentiation of PCDSCs in the presence and absence of purmorphamine. ${ }^{*} P<0.05$.

not only contributed to bone formation but also recruited host cells to form an organized marrow space within areas of new bone (Figure 4C, indicated as BM). Fluorescence microscopy further illustrated that numerous $\mathrm{GFP}^{+}$donor cells formed cuboidal osteoblasts along new bone surface and $\mathrm{GFP}^{+}$osteocytes embedded in the bone tissue (Figure 4D, white arrows). Only a small percentage of osteocytes in bone matrix were found to be negative for GFP, indicating a small contribution of host cells to bone formation (Figure 4D, red arrow). Bone marrow cells within areas of new bone were primarily negative for GFP.

\section{The Hh Pathway Targets Mesenchymal Lineage at the Early Stage of Periosteal \\ Bone Repair}

The strong osteogenic and chondrogenic response of PCDSCs to the Hh agonists prompted us to examine the localization of Hh signals and Hh targeted cells in periosteum-mediated repair. In situ hybridization was performed to determine the regulation of Shh and Ihh genes during repair. Due to poor specificity of the Shh probes as well as potentially very low expression of Shh mRNA in adult tissues, we did not detect Shh expression at the onset of healing. However, we found strong thh gene expression as early as day 5 along periosteum in early prehypertrophic chondrocytes and persisted until day 10 (Figure 5, A-F).

Ptc1 is a direct transcriptional target for Hh signaling and is frequently used as an indicator for $\mathrm{Hh}$ signaling in targeted cells. The insertion of the LacZ gene into the Ptc1 locus disrupts Ptc1 expression. Homozygous Ptc1LacZ mice die during embryonic development, while heterozygote expresses LacZ in a pattern mimicking endogenous gene expression. ${ }^{47-48}$ Using heterozygote Ptc1-LacZ mice, we examined the endogenous Hh signaling during early periosteum healing via X-Gal staining. As demonstrated in Figure $5(\mathrm{G}-\mathrm{H})$, Ptc1-LacZ was detected at the early stage of healing in periosteal cells overlying the bone surface on day 3. At days 5 and 7, Ptc-LacZpositive cells were found in periosteal callus surrounding prehypertrophic chondrocytes. The staining was markedly increased in chondroprogenitors, proliferating chondrocytes (Figure 5, I and J, indicated as Cp), early vascular progenitor cells (Figure $5, \mathrm{~K}$ and $\mathrm{L}$, indicated as $\mathrm{Vs}$ ) and mesenchymal cells (Figure $5, \mathrm{M}$ and $\mathrm{N}$, indicated as Ms). Ptc1-LacZ was also found in osteoblastic cells in new woven bone (Figure 5, $\mathrm{O}$ and $\mathrm{P}$, indicated as Bone). The Ptc1-LacZ staining is consistent with the in situ localization of Ihh and suggests that the Hh signaling pathway, 
A
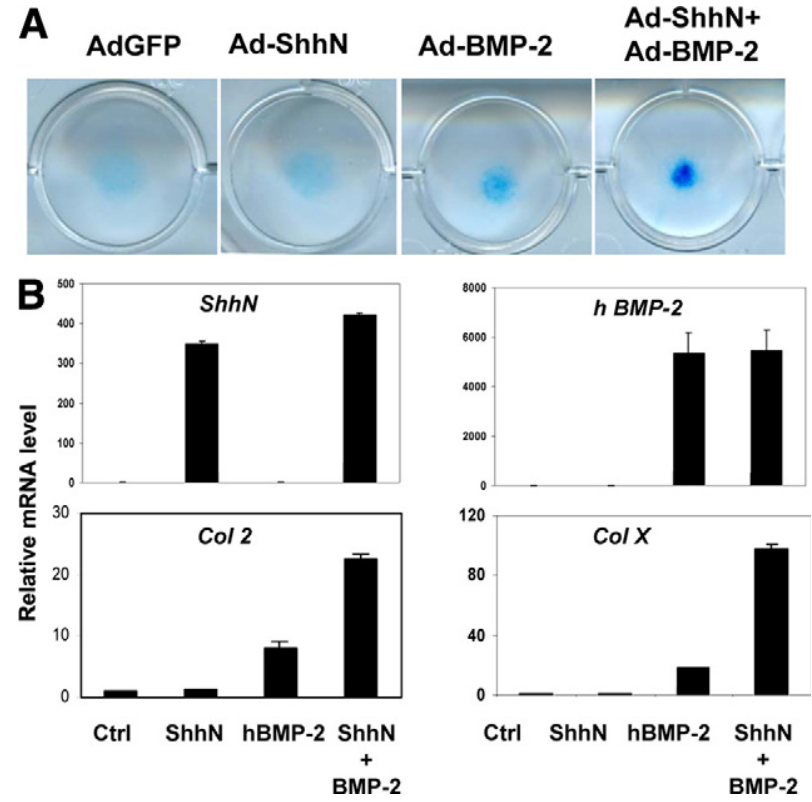

Figure 3. Synergistic induction of chondrogenic differentiation of PCDSCs by BMP-2 and ShhN. A: Alcian blue staining of micromass culture demonstrates chondrogenic differentiation of PCDSCs over 14 days. Note that ShhN induced marked chondrogenesis in cooperation with BMP-2. B: Real time RT-PCR analyses demonstrate the expression of transgene recombinant human BMP-2 and $\operatorname{ShbN}$ along with Col2a1 and ColX gene expression in micromass cultures.

likely the Ihh pathway is involved in regulation of periosteum-dependent endochondral and intramembranous bone formation.

\section{Deletion of Smoothened in Repair Callus Resulted in Significant Reduction of Bone Callus Formation}

Hh signals are transduced through smoothened (Smo), a $G$ protein-coupled seven transmembrane domain protein. Deletion of Smo resulted in early embryonic lethality that prevents detailed study of $\mathrm{Hh}$ signaling in adult bone repair. To overcome this problem, we crossed the conditional deletion mouse model $\mathrm{Smo}^{\mathrm{f} / \mathrm{f}}$ mice with a Tamoxifen inducible RosaCreER mouse model ${ }^{35-36}$ to generate $\mathrm{Smo}^{\mathrm{ff} / \mathrm{f}}$;CreER mice that permit deletion of Smo gene postnatally via Tamoxifen treatment. By crossing RosaCreER with RosaR reporter mice, we have previously demonstrated that this approach can lead to efficient gene recombination in the early periosteum callus with minimal perturbation of the early repair process. ${ }^{36}$

To examine the effect of Smo deletion in bone repair process, we performed bone autograft surgery in control $\mathrm{Smo}^{\mathrm{ft} f}$ and $\mathrm{Smo}^{\mathrm{ftf}}$;CreER mice. TM was injected before surgery and postsurgery every other day for a total of 5 doses in both $\mathrm{Smo}^{\mathrm{f} / \mathrm{f}}$ mice and $\mathrm{Smo}^{\mathrm{ft} / \mathrm{f}}$;CreER mice. Periosteal bone formation was quantified postsurgery at day 17 via microCT and histomorphometric analyses. As shown in Figure 6A, deletion of Smo at the onset of bone healing led to marked reduction of total bone callus formation. MicroCT analyses showed an average of 50\% reduction of bone formation on the host side and a $25 \%$
A

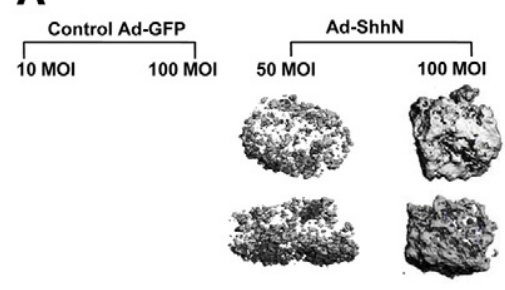

B
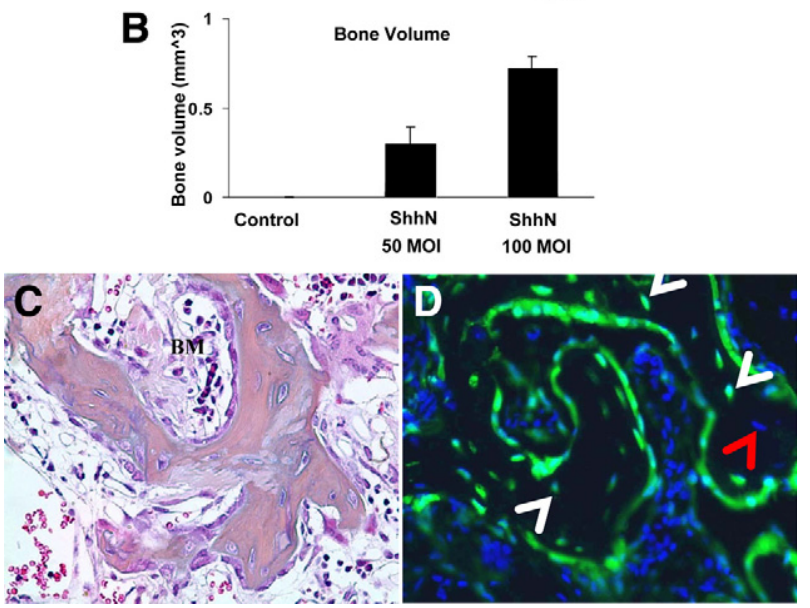

Figure 4. Activation of the Hh pathway in PCDSCs induced robust bone formation in vivo. PCDSCs transduced with Ad-GFP or Ad-ShhN were implanted subcutaneously into the athymic nude mice. Samples were harvested at 8 weeks postimplantation and subsequently examined by microCT. Minimal mineralization or new bone formation were observed in cells infected with Ad-GFP. In contrast, cells infected with Ad-ShhN led to dose-dependent new bone formation within collagen scaffolds $(\mathbf{A})$. Quantitative analyses of new bone volume via microCT are shown in $\mathbf{B}(n=3$ per group, $P<0.05)$ Representative histological section $(\mathbf{C})$ and fluorescence imaging (D) demonstrate that a large number of osteoblasts along the bone surface and osteocytes within the bone matrix (white arrowheads) are positive for GFP. A small number of $\mathrm{GFP}^{-}$osteocytes (red arrowhead) was also found within bone matrix. Furthermore, ectopic bone marrow within areas of newly formed bone is established (indicated as BM in $\mathbf{C}$ ).

reduction of bone on the donor side (Figure 6B, $P<0.05$, $n=15$ per group). Histology analysis further revealed that while Cre-negative mice demonstrated vigorous bone formation at the cortical bone junction, Cre-positive mice demonstrated marked reduction of endochondral bone formation at postsurgery day 17 (Figure 6, C and D). In both host and donor callus, bone volume was reduced by $51 \%$, accompanied by a higher percentage of unmineralized or poorly differentiated cells lingering at the cortical bone junctions. Fibrotic tissue at the cortical bone junction was also significantly more abundant in Cre positive mice than Cre-negative mice (Figure 6, E and F). In addition to reduced bone formation, histology showed that the average size of the total callus in $\mathrm{Smo}^{\mathrm{f} / \mathrm{f}}$; CreER is $46 \%$ smaller than that of the control $\mathrm{Smo}^{\mathrm{f} / \mathrm{f}}$ mice $(P<0.01, n=15)$.

Cellular proliferation in periosteal callus was further examined using PCNA staining. We found that a large number of PCNA-positive chondroprogenitors and chondrocytes were distinctively located around hypertrophic chondrocytes (Figure 6, G-J). Interestingly, PCNA-positive cells appeared to show a similar localization as PtcLacZ-positive cells surrounding hypertrophic chondrocytes (Figure 5, J, L, and N). Furthermore, compared with control Cre-negative mice, we found that PCNA-positive 


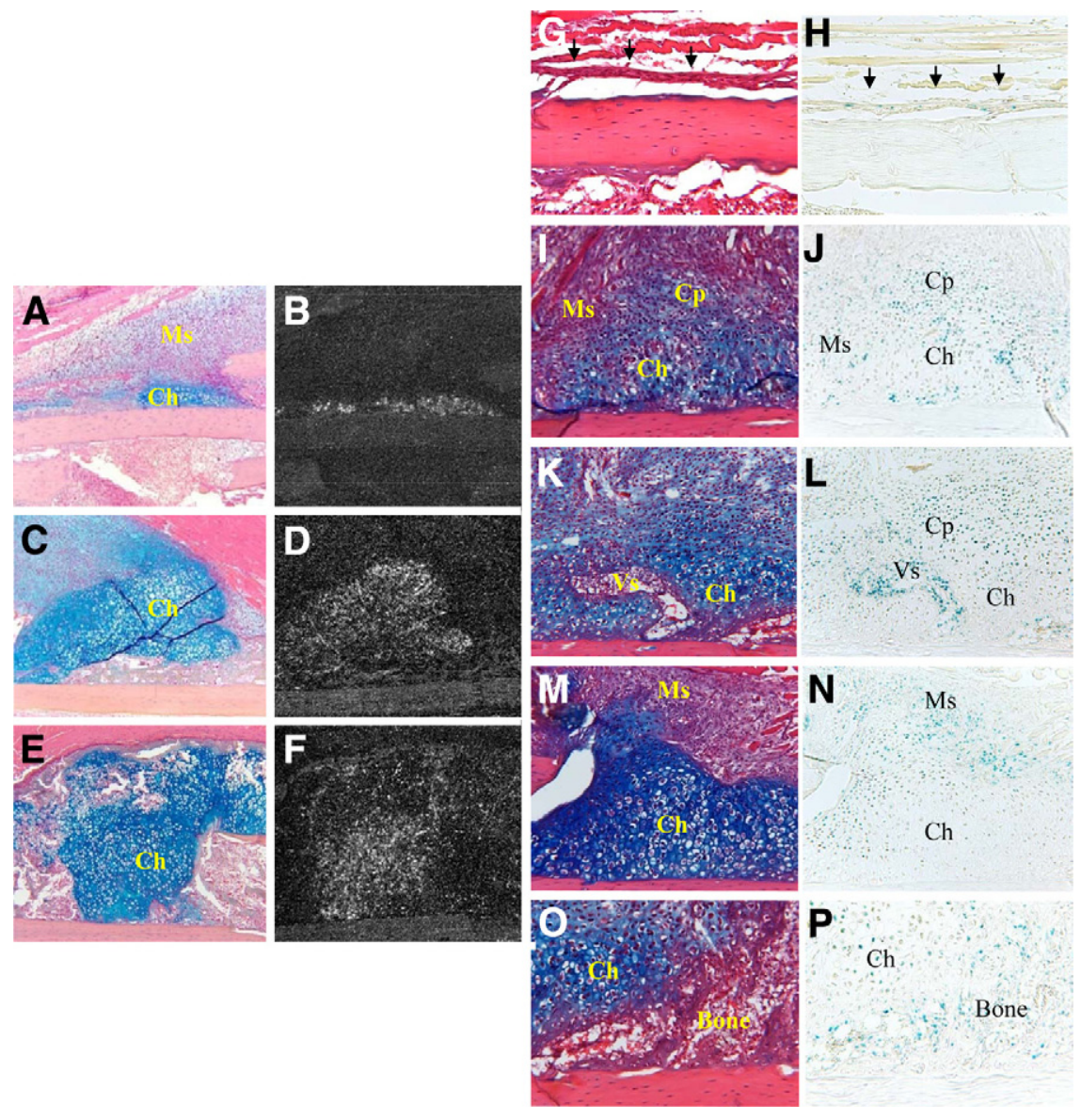

Figure 5. In situ detection of th signaling in periosteal callus. H\&E Alcian blue stained sections (A, C, and $\mathbf{E}$ ) and dark field thh in situ parallel sections $(\mathbf{B}, \mathbf{D}$, and $\mathbf{F})$ of periosteal callus on day 5 (A and $\mathbf{B}), 7(\mathbf{C}$ and $\mathbf{D})$, and 10 (E and F) are shown. In situ hybridization demonstrates induction of $I h b$ gene as early as day 5 in prehypertrophic chondrocytes directly overlying periosteal surface. Induction of the gene further increased by day 7 and peaked at day 10. (Ms, mesenchymal cells; Ch, prehypertrophic cells) H\&E/Alcian blue $(\mathbf{G}, \mathbf{I}, \mathbf{K}, \mathbf{M}$, and $\mathbf{O})$ and corresponding X-gal $(\mathbf{H}, \mathbf{J}, \mathbf{L}, \mathbf{N}$, and $\mathbf{P})$ stained sections of the callus from Ptc1-LacZ mice obtained on day $3(\mathbf{G}$ and $\mathbf{H})$ and day $7(\mathbf{I}-\mathbf{P})$ are shown. Early on Ptc-lacZ was detected in some periosteal cells above bone surface (arrows in $\mathbf{G}$ and H). During endochondral ossification Ptc-lacZ was detected in mesenchymal cells (Ms in $\mathbf{J}$ and $\mathbf{N}$ ), chondroprogenitors and proliferating chondrocytes (Cp in $\mathbf{J}$ and $\mathbf{L}$ ), as well as vascular endothelial cells (Vs in $\mathbf{L}$ ). Ptc1-LacZ signals were also identified in osteoblastic cells in new woven bone (Bone in $\mathbf{P}$ ). cells surrounding hypertrophic chondrocytes in Smo deleted periosteal callus were reduced by nearly 40\% (Figure $6 \mathrm{~K}, n=6)$.

To further examine the effects of Hh signaling on differentiation of the periosteal mesenchymal progenitors, we isolated PCDSCs from TM-treated $\mathrm{Smo}^{\mathrm{f} / \mathrm{f}}$ or $\mathrm{Smo}^{\mathrm{f} / \mathrm{f}}$; CreER mice 5 days after the autograft surgery as described in the Materials and Methods section. Cells harvested at passage 1 were used to examine osteogenic differentiation of PCDSCs in the presence and absence of $\mathrm{Hh}$ agonist Purmorphamine. As shown in Figure 7, A and $B$, osteogenic differentiation was markedly reduced in cells isolated from $\mathrm{Smo}^{\mathrm{f} / \mathrm{f}}$;CreER bone grafts compared to cells from Smo ${ }^{\mathrm{f} / \mathrm{f}}$, as indicated by ALP staining and real-time RT-PCR analyses. Treatment of Purmorphamine resulted in significant induction of osteogenic differentiation in Smo ${ }^{\mathrm{f} / \mathrm{f}}$ cells. In contrast, the induction of osteogenesis by Purmorphamine was markedly reduced in $\mathrm{Smo}^{\mathrm{f} / \mathrm{f}} ;$ CreER cells. Gene analyses further demonstrated an average of $80 \%$ reduction of Smo gene expression in isolated $\mathrm{Smo}^{\mathrm{f} / \mathrm{f}}$;CreER cells, indicating that in vivo TM treatment led to efficient deletion of Smo gene as a result of Cre-mediated gene recombination. Similar results were found when Hh inhibitor Cyclopamine was used to inhibit the endogenous $\mathrm{Hh}$ signaling as demonstrated in Figure 7C. Treatment of Cyclopamine resulted in suppression of osteogenic differentiation of PCDSCs in a dose-dependent manner.

\section{Discussion}

Due to early embryonic lethality, the role of the Hh pathway in adult bone repair remains unknown. Using a welldefined bone graft repair model in mice, in our current study, we showed that: 1) Hh signaling was enhanced in early periosteal callus during cortical bone repair, targeting early chondroprogenitors, undifferentiated mesenchyme, perivascular cells, as well as osteoblasts; 2) Activation of Hh signaling enhanced osteogenic and chondrogenic differentiation of mesenchymal progenitors derived from periosteum callus (PCDSCs) in synergy with BMP-2; 3) Overexpression of ShhN peptide in isolated PCDSCs led to robust bone formation in vivo; 4) Postnatal deletion of Smo, a receptor that transduces all $\mathrm{Hh}$ signaling, impaired osteogenic differentiation of periosteal mesenchymal progenitors in vitro, resulted in $50 \%$ reduction of periosteal bone callus formation in vivo. Taken together, these data demonstrate that activation of the Hh pathway at the early stage of healing is required for efficient periosteum-mediated repair and regeneration.

Previous studies have implicated both Ihh and Shh in postnatal bone repair. ${ }^{3,19,49-53}$ Using in situ hybridization, Miyaji et al demonstrated that Shh mRNA expression was induced at day 2 in periosteal tissues after fracture. ${ }^{51}$ In a study using 5-day-old mice in a bone fracture-healing model, Vortkamp et al show that Ihh is expressed in 
A

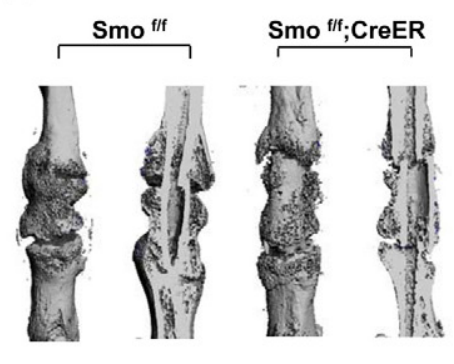

B

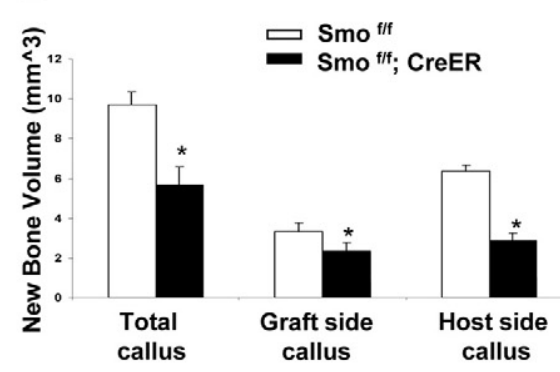

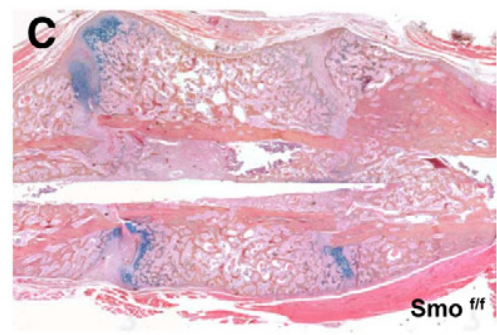

E
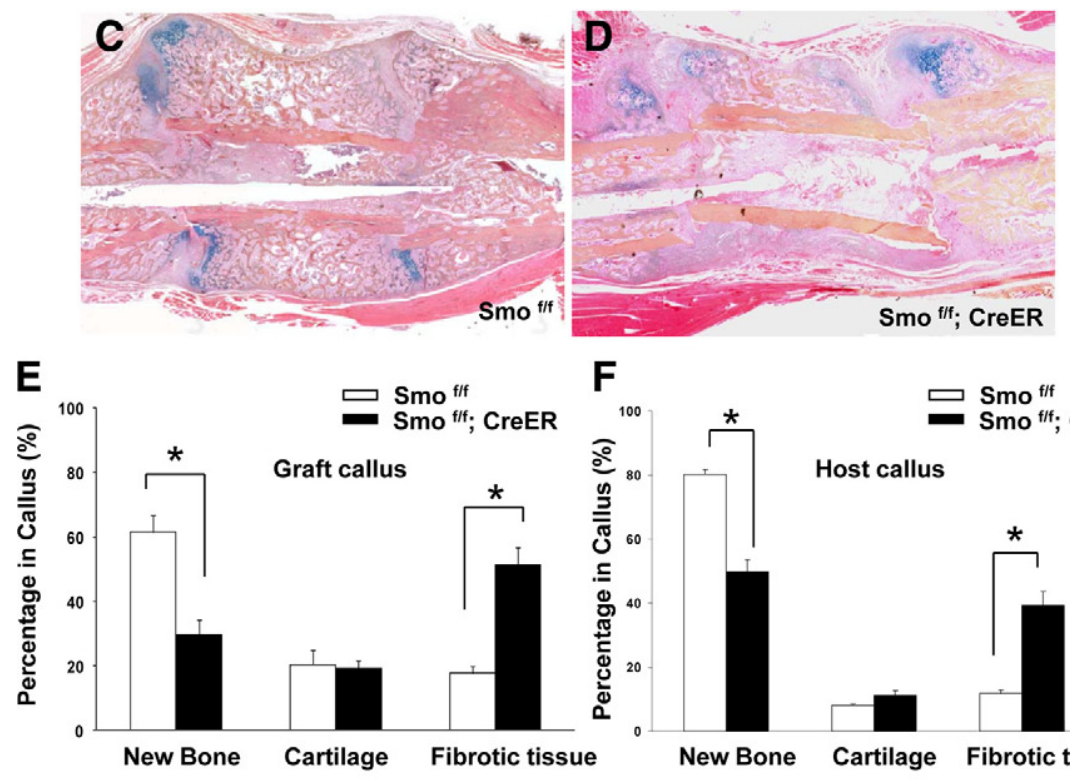

$F$
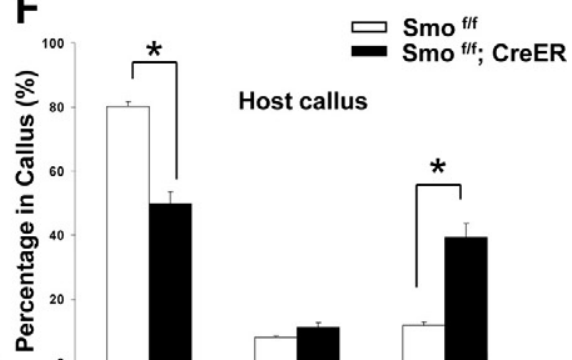

New Bone
Host callus

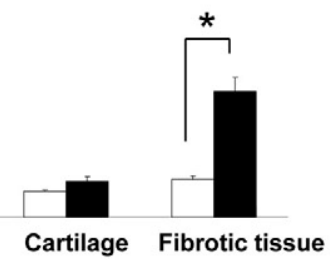

K

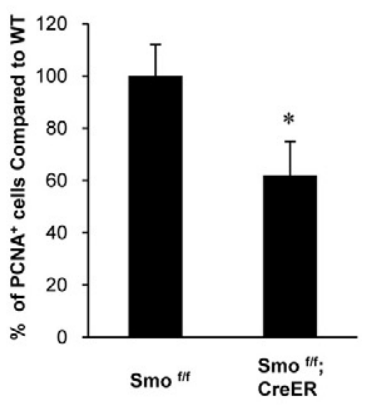

Figure 6. Deletion of Smo led to reduced bone autograft repair. Bone autograft surgeries were performed in $\mathrm{Smo}^{\mathrm{f} / \mathrm{f}}$ or $\mathrm{Smo}^{\mathrm{f} / \mathrm{f}}$; CreER mice as described. Tamoxifen (TM) was injected before and after surgery for a total of five times every other day. Samples were harvested at postsurgery day 17 for MicroCT and histological analyses. Representative MicroCT images (A) show reduced periosteal callus formation in $\mathrm{Smo}^{\mathrm{f} / \mathrm{f}}$, CreER mice compared to $\mathrm{Smo}^{\mathrm{f} / \mathrm{f}}$ mice. Quantitative analyses (B) on both host side and donor side demonstrate reduced periosteal new bone volume in $\mathrm{Smo}^{\mathrm{f} / \mathrm{f}}$; CreER callus $\left({ }^{*} P<0.01, n=\right.$ 15). Representative histology (C and D) and quantitative analyses of bone callus on the graft side (E) and host side (F) further show reduced size of bone callus formation and significant reduction of new bone formation in $\mathrm{Smo}^{\mathrm{f} / \mathrm{f}}$;CreER compared to $\mathrm{Smo}^{\mathrm{f} / \mathrm{f}}\left({ }^{*} P<0.05, n=15\right)$. H\&E/ Alcian blue (G and $\mathbf{I})$ and corresponding PCNA staining section ( $\mathbf{H}$ and $\mathbf{J}$ ) show PCNA-positive cells surrounding hypertrophic chondrocytes (Ch) in periosteal callus. Compared to $\mathrm{Smo}^{\mathrm{f} / \mathrm{f}}$ callus $(\mathbf{G}$ and $\mathbf{H}), \mathrm{Smo}^{\mathrm{f} / \mathrm{f}}$; CreER periosteal callus (I and $\mathbf{J}$ ) exhibits reduced number of PCNApositive cells around hypertrophic chondrocytes. Quantitative analyses (K) demonstrate a significant reduction of PCNA-positive cells in periosteal callus. ${ }^{*} P<0.05, n=6$.
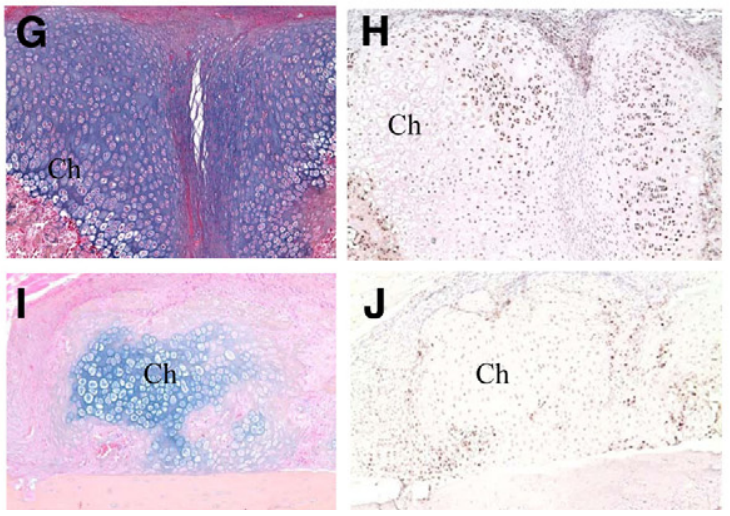

hypertrophic chondrocytes in fracture callus associated with increased Ptc1, Gli1 and PTHrP receptor expression in the surrounding callus tissue. ${ }^{49}$ In our current study, we did not find convincing evidence for the induction of Shh in early periosteal callus due to technical difficulties for in situ hybridization in adult tissue. However, we did find strong Ihh expression as early as day 5 at the onset of healing in periosteum callus (Figure 5). Remarkably, using Ptc1-LacZ heterozygotes, we found that Hh signaling targeted mesenchymal lineages including osteoblasts, chondrocytes, and vascular lining cells surrounding prehypertrophic chondrocytes in early periosteal callus (Figure 5). The timing and location of Hh signaling suggest that hedgehog, most likely Ihh signaling, plays a role in proliferation and differentiation of mesenchymal lineages at the early stage of endochondral bone repair.

Indian hedgehog has a critical role in perichondriummediated collarbone formation during early skeletogenesis. Global deletion of Ihh results in the elimination of collarbone formation, a process that involves both BMP-2 and Wnt signaling pathways. ${ }^{20-21,54-57}$ Because periosteum originates from embryonic perichondrium, it is conceivable that the deficient periosteum healing could implicate both BMP-2 and Wnt pathways. In our current study, we found that the Hh agonist enhance endogenous BMP-2 expression. Hh agonist further blocked the expression of Wnt antagonists SFRP-1 and SFRP-2, indicating the involvement of Wnt signaling downstream of 

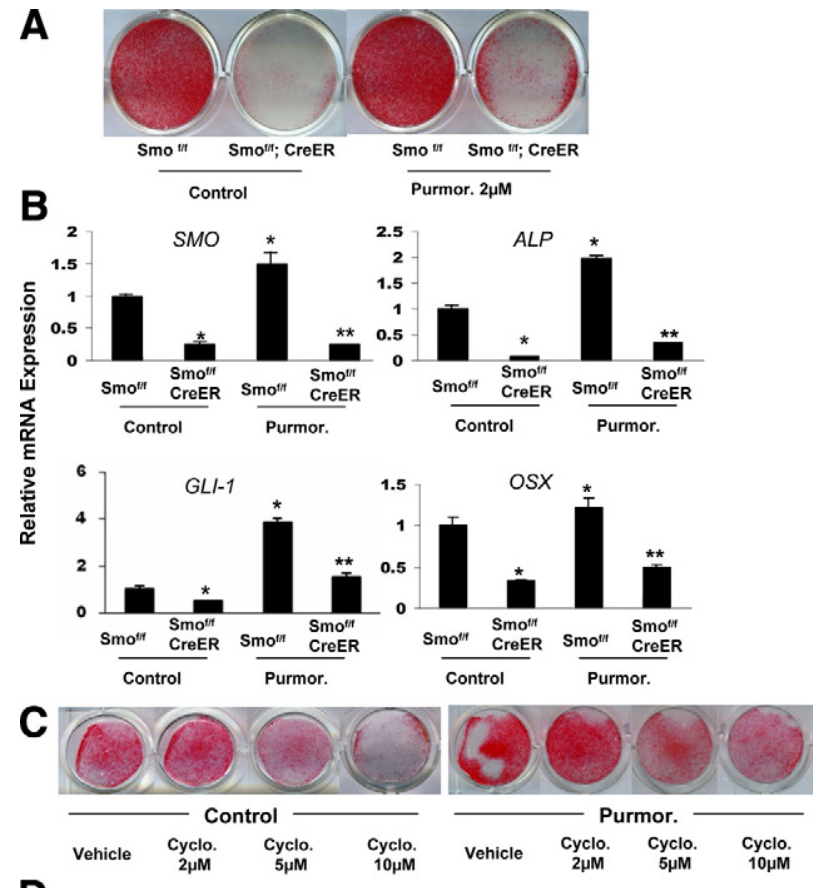

D

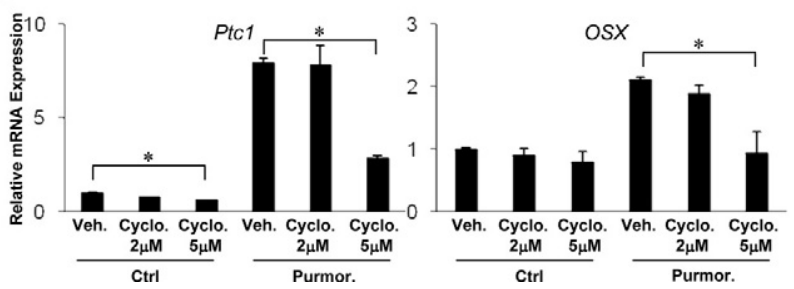

Figure 7. Deletion of Smo led to decreased osteogenic differentiation of periosteum mesenchymal progenitors. Bone autograft surgery was performed in $\mathrm{Smo}^{\mathrm{f} / \mathrm{f}}$ or $\mathrm{Smo}^{\mathrm{f} / \mathrm{f}}$; CreER mice as described. Tamoxifen were injected before and after surgery a total of three times. Periosteal cells were isolated from bone autografts at postsurgery day 5. Osteogenic differentiation was examined via ALP staining and real-time RT-PCR analyses. Deletion of Smo at the onset of repair led to decreased osteogenic differentiation of PCDSCs and blunted purmorphamine induced differentiation as indicated by ALP staining $(\mathbf{A})$ and real-time PCR analyses $(\mathbf{B}) .{ }^{*} P<0.05 ;{ }^{* * *} P<0.01$. The Hh inhibitor cyclopamine demonstrates a dose-dependent suppression of ALP staining in PCDSCs isolated from wild-type mice (C). RT-PCR analyses demonstrate that treatment of cyclopamine significantly suppresses the expression of Ptc1 and OSX gene at $5 \mu \mathrm{mol} / \mathrm{L} .{ }^{*} P<0.05$.

Hh signaling. Because both Wht and BMP-2 pathways have been shown to play significant roles in repair, ${ }^{5-60}$ future studies are necessary to determine Hh signaling interactions with BMP-2 and Wnt pathway in repair and regeneration.

Both Shh and Ihh have been shown to play key roles in proliferation and self-renewal of stem/progenitor cells. ${ }^{61-63}$ The long bones of Ihh mutants are only $20 \%$ the length of those of their wild-type littermates at birth, a phenotype that correlates with a pronounced reduction in cellular proliferation. ${ }^{62}$ Consistently, in our current study we found that deletion of Smoothened resulted in a nearly $50 \%$ reduction of the size of the bone callus at the cortical bone junction as indicated by quantitative MicroCT and histomorphometric analyses. Furthermore, we found significant reduction of PCNA-positive cells around hypertrophic chondrocytes in Smo-deleted periosteal callus (Figure 6). This result suggests that $\mathrm{Hh}$ signaling is in- volved in expansion of bone/cartilage callus formation during early endochondral bone repair. The notion is further supported by the localization of Ptc1-LacZ signals in early chondroprogenitors and proliferating chondrocytes surrounding prehypertrophic chondrocytes, suggesting a role of Ihh in driving the expansion of callus formation during the early stage of endochondral bone repair.

Using an adenovirus that expresses a secreted form of ShhN peptide, we showed that activation of Hh signaling in periosteal mesenchymal progenitors induced robust bone formation in vivo (Figure 4). This finding provides the rationale for using Hh-activated mesenchymal progenitors for cell-based therapy for repair of bony defects. Although the effect of Shh in the induction of bone formation has been reported in other mesenchymal cell lines, ${ }^{27,64-66}$ the potency of Hh protein in inducing in vivo bone formation and repair remains unclear. Hh protein may elicit differential effects on progenitor cells derived from various sources. Compared with bone marrow stromal cells and adipose-derived mesenchymal progenitors, we found that the isolated PCDSCs were much more responsive to either BMP-2 or Hh signals (Supplemental Figure 2 at $h$ ttp://ajp.amjpathol.org). Furthermore, isolated PCDSCs demonstrated a high degree of proliferation potency and expandability in vitro (Supplemental Figure $1 \mathrm{~A}$ at http://ajp.amjpathol.org), indicating that these cells can be used as an optimal cellular source for bone regeneration. Further experiments are underway to determine the efficacy of ShhN in repair of bone allograft, whose healing is vastly inferior to autograft due to the absence of live periosteum. ${ }^{33}$

One of the great challenges in understanding the molecular pathways that control periosteum-initiated repair and regeneration is the lack of an adequate animal model that could be used to define periosteum-initiated repair. In our previous studies, we established a bone graft transplantation model that allows us to use various transgenic mice to track cell fate and analyze the contribution of periosteum in repair. ${ }^{31-34,36,39-40,67-68}$ Using this transplantation model, in this current study, we further demonstrated a reproducible method to isolate mesenchymal progenitors derived from the donor periosteum. FACS analyses showed that more than half of these isolated cells were derived from the GFP+ donor periosteum. This result is consistent with our previous publication, which shows a major contribution of donor periosteal progenitor cells in graft healing. Furthermore, our study shows that over $90 \%$ of all isolated cells (including GFP ${ }^{+}$ and $\mathrm{GFP}^{-}$) express mesenchymal stem cell markers and display triple lineage differentiation potential. When stimulated with osteogenic factors, they further contribute to in vivo bone formation and demonstrated the capability to form organized bone marrow at an ectopic site (Figure 5D). Compared to mesenchymal progenitors isolated from fat and bone marrow, these cells were more responsive to BMP-2 and $\mathrm{Hh}$ agonists, suggesting its unique role in repair and regeneration (Supplemental Figure 2 at http://ajp.amjpathol.org). The isolation of mesenchymal progenitors from early periosteum callus demonstrates the existence of a unique pool of mesenchymal progen- 
itors during bone repair. Identifying signals or signaling pathways that stimulate the differentiation of these cells during repair could provide insights into novel therapeutic strategies for the treatment of delayed or impaired cortical bone healing.

In conclusion, our current study demonstrates a serial of novel approaches to define the role of Hh signaling in periosteum-mediated repair. In addition to Hh pathway, these approaches can also be used to define other molecule pathways implicated in periosteum-mediated repair and regeneration and further provide the molecular basis for developing new therapeutic strategies to treat patients with compromised periosteum that are at high risk of nonunion.

\section{Acknowledgments}

We thank Drs. Regis O'Keefe and Edward Schwarz for helpful discussion and Ryan Tiemey, Michael Thullen, and Dr. Chao Xie for their assistance with histology and microCT analyses. Finally we thank Kimberly Napoli for careful editing of this manuscript.

\section{References}

1. Allen MR, Hock JM, Burr DB: Periosteum: biology, regulation, and response to osteoporosis therapies. Bone 2004, 35:1003-1012

2. Wlodarski KH: Normal and heterotopic periosteum. Clin Orthop Relat Res 1989, 265-277

3. Ferguson C, Alpern E, Miclau T, Helms JA: Does adult fracture repair recapitulate embryonic skeletal formation? Mech Dev 1999, 87:57-66

4. Sandell LJ, Adler P: Developmental patterns of cartilage. Front Biosci 1999, 4:D731-742

5. Zuscik MJ, Hilton MJ, Zhang X, Chen D, O'Keefe RJ: Regulation of chondrogenesis and chondrocyte differentiation by stress. J Clin Invest 2008, 118:429-438

6. Einhorn TA: The cell and molecular biology of fracture healing. Clin Orthop 1998, S7-21

7. Gerstenfeld LC, Cullinane DM, Barnes GL, Graves DT, Einhorn TA: Fracture healing as a post-natal developmental process: molecular, spatial, and temporal aspects of its regulation. J Cell Biochem 2003, 88:873-884

8. Ingham PW, McMahon AP: Hedgehog signaling in animal development: paradigms and principles. Genes Dev 2001, 15:3059-3087

9. McMahon AP, Ingham PW, Tabin CJ: Developmental roles and clinical significance of hedgehog signaling. Curr Top Dev Biol 2003, 53:1-114

10. Baker DP, Taylor FR, Pepinsky RB: Purifying the hedgehog protein and its variants. Methods Mol Biol 2007, 397:1-22

11. Ogden SK, Fei DL, Schilling NS, Ahmed YF, Hwa J, Robbins DJ: G protein Galphai functions immediately downstream of Smoothened in Hedgehog signalling. Nature 2008, 456:967-970

12. Riobo NA, Saucy B, Dilizio C, Manning DR: Activation of heterotrimeric G proteins by Smoothened. Proc Natl Acad Sci USA 2006, 103:12607-12612

13. Ingham PW: Transducing Hedgehog: the story so far. EMBO J 1998, 17:3505-3511

14. Zhang XM, Ramalho-Santos M, McMahon AP: Smoothened mutants reveal redundant roles for Shh and Ihh signaling including regulation of L/R symmetry by the mouse node. Cell 2001, 106:781-792

15. van den Heuvel M, Ingham PW: smoothened encodes a receptor-like serpentine protein required for hedgehog signalling. Nature 1996, 382:547-551

16. Sasaki H, Nishizaki Y, Hui C, Nakafuku M, Kondoh H: Regulation of Gli2 and Gli3 activities by an amino-terminal repression domain: implication of Gli2 and Gli3 as primary mediators of Shh signaling. Development 1999, 126:3915-3924

17. Wang B, Li Y: Evidence for the direct involvement of $\{$ beta $\} \operatorname{TrCP}$ in Gli3 protein processing. Proc Natl Acad Sci USA 2006, 103:33-38

18. Pan $Y$, Bai CB, Joyner AL, Wang B: Sonic hedgehog signaling regulates Gli2 transcriptional activity by suppressing its processing and degradation. Mol Cell Biol 2006, 26:3365-3377

19. Ferguson CM, Miclau T, Hu D, Alpern E, Helms JA: Common molecular pathways in skeletal morphogenesis and repair. Ann NY Acad Sci 1998, 857:33-42

20. Hu H, Hilton MJ, Tu X, Yu K, Ornitz DM, Long F: Sequential roles of Hedgehog and Wnt signaling in osteoblast development. Development 2005, 132:49-60

21. Rodda SJ, McMahon AP: Distinct roles for Hedgehog and canonical Wnt signaling in specification, differentiation and maintenance of osteoblast progenitors. Development 2006, 133:3231-3244

22. Fan CM, Porter JA, Chiang C, Chang DT, Beachy PA, Tessier-Lavigne M: Long-range sclerotome induction by sonic hedgehog: direct role of the amino-terminal cleavage product and modulation by the cyclic AMP signaling pathway. Cell 1995, 81:457-465

23. Long F, Zhang XM, Karp S, Yang Y, McMahon AP: Genetic manipulation of hedgehog signaling in the endochondral skeleton reveals a direct role in the regulation of chondrocyte proliferation. Development 2001, 128:5099-5108

24. Long F, Chung UI, Ohba S, McMahon J, Kronenberg HM, McMahon AP: Ihh signaling is directly required for the osteoblast lineage in the endochondral skeleton. Development 2004, 131:1309-1318

25. Chung UI, Schipani E, McMahon AP, Kronenberg HM: Indian hedgehog couples chondrogenesis to osteogenesis in endochondral bone development. J Clin Invest 2001, 107:295-304

26. Shimoyama A, Wada M, Ikeda F, Hata K, Matsubara T, Nifuji A, Noda M, Amano K, Yamaguchi A, Nishimura R, Yoneda T: Ihh/Gli2 signaling promotes osteoblast differentiation by regulating Runx2 expression and function. Mol Biol Cell 2007, 18:2411-2418

27. Enomoto-Iwamoto M, Nakamura T, Aikawa T, Higuchi Y, Yuasa T, Yamaguchi A, Nohno T, Noji S, Matsuya T, Kurisu K, Koyama E, Pacifici M, Iwamoto M: Hedgehog proteins stimulate chondrogenic cell differentiation and cartilage formation. J Bone Miner Res 2000, 15:1659-1668

28. Shea CM, Edgar CM, Einhorn TA, Gerstenfeld LC: BMP treatment of C3H10T1/2 mesenchymal stem cells induces both chondrogenesis and osteogenesis. J Cell Biochem 2003, 90:1112-1127

29. Zehentner BK, Leser U, Burtscher H: BMP-2 and sonic hedgehog have contrary effects on adipocyte-like differentiation of C3H10T1/2 cells. DNA Cell Biol 2000, 19:275-281

30. Fontaine C, Cousin W, Plaisant M, Dani C, Peraldi P: Hedgehog signaling alters adipocyte maturation of human mesenchymal stem cells. Stem Cells 2008, 26:1037-1046

31. Tiyapatanaputi P, Rubery PT, Carmouche J, Schwarz EM, O'Keefe RJ, Zhang X: A novel murine segmental femoral graft model. J Orthop Res 2004, 22:1254-1260

32. Xie C, Reynolds D, Awad H, Rubery PT, Pelled G, Gazit D, Guldberg RE, Schwarz EM, O'Keefe RJ, Zhang X: Structural bone allograft combined with genetically engineered mesenchymal stem cells as a novel platform for bone tissue engineering. Tissue Eng 2007, 13:435-445

33. Zhang X, Xie C, Lin AS, Ito H, Awad H, Lieberman JR, Rubery PT, Schwarz EM, O'Keefe RJ, Guldberg RE: Periosteal progenitor cell fate in segmental cortical bone graft transplantations: implications for functional tissue engineering. J Bone Miner Res 2005, 20:2124-2137

34. Zhang X, Awad HA, O'Keefe RJ, Guldberg RE, Schwarz EM: A perspective: engineering periosteum for structural bone graft healing. Clin Orthop Relat Res 2008, 466:1777-1787

35. Badea TC, Wang Y, Nathans J: A noninvasive genetic/pharmacologic strategy for visualizing cell morphology and clonal relationships in the mouse. J Neurosci 2003, 23:2314-2322

36. Xie C, Xue M, Wang Q, Schwarz EM, O'Keefe RJ, Zhang X: Tamoxifeninducible CreER-mediated gene targeting in periosteum via bonegraft transplantation. J Bone Joint Surg Am 2008, 90(Suppl 1):9-13

37. Lou H, Crystal RG, Leopold PL: Enhanced efficacy of cholesterolminus sonic hedgehog in postnatal skin. Mol Ther 2005, 12:575-578

38. Chen M, Lichtler AC, Sheu TJ, Xie C, Zhang X, O'Keefe RJ, Chen D: Generation of a transgenic mouse model with chondrocyte-specific 
and tamoxifen-inducible expression of Cre recombinase. Genesis 2007, 45:44-50

39. Ito H, Koefoed M, Tiyapatanaputi P, Gromov K, Goater JJ, Carmouche J, Zhang X, Rubery PT, Rabinowitz J, Samulski RJ, Nakamura T, Soballe K, O'Keefe RJ, Boyce BF, Schwarz EM: Remodeling of cortical bone allografts mediated by adherent rAAV-RANKL and VEGF gene therapy. Nat Med 2005, 11:291-297

40. Xie C, Ming X, Wang Q, Schwarz EM, Guldberg RE, O'Keefe RJ, Zhang $X$ : COX-2 from the injury milieu is critical for the initiation of periosteal progenitor cell mediated bone healing. Bone 2008 , 43:1075-1083

41. Krebsbach PH, Kuznetsov SA, Satomura K, Emmons RV, Rowe DW, Robey PG: Bone formation in vivo: comparison of osteogenesis by transplanted mouse and human marrow stromal fibroblasts. Transplantation 1997, 63:1059-1069

42. Shi S, Gronthos S, Chen S, Reddi A, Counter CM, Robey PG, Wang $\mathrm{CY}$ : Bone formation by human postnatal bone marrow stromal stem cells is enhanced by telomerase expression. Nature Biotechnol 2002, 20:587-591

43. Zhang X, Schwarz EM, Young DA, Puzas JE, Rosier RN, O'Keefe RJ: Cyclooxygenase-2 regulates mesenchymal cell differentiation into the osteoblast lineage and is critically involved in bone repair. J Clin Invest 2002, 109:1405-1415

44. Xie C, Liang B, Xue M, Lin AS, Loiselle A, Schwarz EM, Guldberg RE, O'Keefe RJ, Zhang X: Rescue of impaired fracture healing in COX-2-/mice via activation of prostaglandin E2 receptor subtype 4. Am J Pathol 2009, 175:772-785

45. Gang EJ, Bosnakovski D, Figueiredo CA, Visser JW, Perlingeiro RC: SSEA-4 identifies mesenchymal stem cells from bone marrow. Blood 2007, 109:1743-1751

46. Katoh $Y$, Katoh M: WNT antagonist. SFRP1, is Hedgehog signaling target, Int J Mol Med 2006, 17:171-175

47. Milenkovic L, Goodrich LV, Higgins KM, Scott MP: Mouse patched1 controls body size determination and limb patterning. Development 1999, 126:4431-4440

48. Goodrich LV, Milenkovic L, Higgins KM, Scott MP: Altered neural cell fates and medulloblastoma in mouse patched mutants. Science 1997, 277:1109-1113

49. Vortkamp A, Pathi S, Peretti GM, Caruso EM, Zaleske DJ, Tabin CJ: Recapitulation of signals regulating embryonic bone formation during postnatal growth and in fracture repair. Mech Dev 1998, 71:65-76

50. Beachy PA, Karhadkar SS, Berman DM: Tissue repair and stem cell renewal in carcinogenesis. Nature 2004, 432:324-331

51. Miyaji T, Nakase T, Iwasaki M, Kuriyama K, Tamai N, Higuchi C, Myoui A, Tomita T, Yoshikawa $\mathrm{H}$ : Expression and distribution of transcripts for sonic hedgehog in the early phase of fracture repair. Histochem Cell Biol 2003, 119:233-237

52. Murakami S, Noda M: Expression of Indian hedgehog during fracture healing in adult rat femora. Calcif Tissue Int 2000, 66:272-276

53. Meyer RA, Jr., Meyer MH, Tenholder M, Wondracek S, Wasserman R, Garges P: Gene expression in older rats with delayed union of femoral fractures. J Bone Joint Surg Am 2003, 85-A:1243-1254

54. Maeda Y, Nakamura E, Nguyen MT, Suva LJ, Swain FL, Razzaque MS, Mackem S, Lanske B: Indian Hedgehog produced by postnatal chondrocytes is essential for maintaining a growth plate and trabecular bone. Proc Natl Acad Sci USA 2007, 104:6382-6387

55. Minina E, Wenzel HM, Kreschel C, Karp S, Gaffield W, McMahon AP Vortkamp A: BMP and Ihh/PTHrP signaling interact to coordinate chondrocyte proliferation and differentiation. Development 2001, 128:4523-4534

56. Zhao M, Qiao M, Harris SE, Chen D, Oyajobi BO, Mundy GR: The zinc finger transcription factor Gli2 mediates bone morphogenetic protein 2 expression in osteoblasts in response to hedgehog signaling. Mol Cell Biol 2006, 26:6197-6208

57. Garrett IR, Chen D, Gutierrez G, Zhao M, Escobedo A, Rossini G Harris SE, Gallwitz W, Kim KB, Hu S, Crews CM, Mundy GR: Selective inhibitors of the osteoblast proteasome stimulate bone formation in vivo and in vitro. J Clin Invest 2003, 111:1771-1782

58. Tsuji K, Bandyopadhyay A, Harfe BD, Cox K, Kakar S, Gerstenfeld L, Einhorn T, Tabin CJ, Rosen V: BMP2 activity, although dispensable for bone formation, is required for the initiation of fracture healing. Nat Genet 2006, 38:1424-1429

59. Chen Y, Whetstone HC, Lin AC, Nadesan P, Wei Q, Poon R, Alman $\mathrm{BA}$ : Beta-catenin signaling plays a disparate role in different phases of fracture repair: implications for therapy to improve bone healing. PLoS Med 2007, 4:e249

60. Chen Y, Alman BA: Wnt pathway, an essential role in bone regeneration. J Cell Biochem 2009, 106:353-362

61. Mimeault M, Batra SK: Concise review: recent advances on the significance of stem cells in tissue regeneration and cancer therapies. Stem Cells 2006, 24:2319-2345

62. St-Jacques B, Hammerschmidt M, McMahon AP: Indian hedgehog signaling regulates proliferation and differentiation of chondrocytes and is essential for bone formation. Genes Dev 1999, 13:2072-2086

63. Machold R, Hayashi S, Rutlin M, Muzumdar MD, Nery S, Corbin JG Gritli-Linde A, Dellovade T, Porter JA, Rubin LL, Dudek H, McMahon AP, Fishell G: Sonic hedgehog is required for progenitor cell maintenance in telencephalic stem cell niches. Neuron 2003, 39:937-950

64. Edwards PC, Ruggiero S, Fantasia J, Burakoff R, Moorji SM, Paric E, Razzano P, Grande DA, Mason JM: Sonic hedgehog gene-enhanced tissue engineering for bone regeneration. Gene Ther 2005, 12:75-86

65. Kinto N, Iwamoto M, Enomoto-Iwamoto M, Noji S, Ohuchi H, Yoshioka H, Kataoka H, Wada Y, Yuhao G, Takahashi HE, Yoshiki S, Yamaguchi A: Fibroblasts expressing Sonic hedgehog induce osteoblast differentiation and ectopic bone formation. FEBS Lett 1997, 404:319-323

66. Yuasa $T$, Kataoka $H$, Kinto $N$, Iwamoto $M$, Enomoto-Iwamoto $M$, lemura S, Ueno N, Shibata $Y$, Kurosawa H, Yamaguchi A: Sonic hedgehog is involved in osteoblast differentiation by cooperating with BMP-2. J Cell Physiol 2002, 193:225-232

67. Zhang X, Naik A, Xie C, Reynolds D, Palmer J, Lin A, Awad H, Guldberg R, Schwarz E, O'Keefe R: Periosteal stem cells are essential for bone revitalization and repair. J Musculoskelet Neuronal Interact 2005, 5:360-362

68. Koefoed M, Ito H, Gromov K, Reynolds DG, Awad HA, Rubery PT, Ulrich-Vinther M, Soballe K, Guldberg RE, Lin AS, O'Keefe RJ, Zhang $X$, Schwarz EM: Biological Effects of rAAV-caAlk2 Coating on Structural Allograft healing. Mol Ther 2005, 12:212-218 